\title{
Acute polyneuropathy in critically ill patients
}

\author{
J. B. Lopez Messa and A. García \\ Intensive Care Unit and Neurophysiology Unit, Hospital General "Rio Carrión”, Palencia, Spain
}

Received: 3 March 1989; accepted: 28 August 1989

\begin{abstract}
We studied five patients in the intensive care unit (ICU) with acute polyneuropathy. All had previously presented severe infectious processes, accompanied by diverse organ failure accompanied by the Adult Respiratory Distress Syndrome (ARDS) in all cases. Two patients died and the three survivors suffered severe motor deficiencies. Electromyographic studies revealed axonal damage which predominately affected motor neurons. Cerebrospinal fluid was normal in all the patients except one, who showed a moderate increase of lymphocytes. The common causes of polyneuropathy were excluded, but in all cases a nutritional disorder was detected, based on laboratory values of proteins, serum albumin and transferrin. We conclude that polyneuropathy is relatively frequent among critically ill patients and must be closely monitored because of diagnostic difficulties and the repercussions on the progress of these patients. In spite of uncertainties about its cause, it appears to be related to severe infectious processes, ARDS, and nutritional disorders.
\end{abstract}

Key words: Polyneuropathy - Multiorgan failure Adult Respiratory Distress Syndrome - Sepsis - Malnutrition

The description of acute polyneuropathy in intensive care unit (ICU) patients, generally associated with severe infectious processes and Acute Respiratory Failure (ARF), is a recent occurrence [1-5], and this disorder is poorly understood. In an attempt to establish the characteristics and possible factors contributing to the development of this disorder, patients in our unit with acute polyneuropathy were studied using a previously established protocol.

\section{Material and methods}

\section{Patients and methods}

We studied all patients admitted to the ICU for a variety of reasons. At presentation none of the patients had any neurological abnormalities but all developed the same pathological pattern, consisting of a motor deficit in the extremities and an electromyographic study compatible with the diagnosis of polyneuropathy. We excluded those patients who presented with these symptoms at the time of admission or those who already suffered from polyneuropathy.

The following data were recorded: age, reason for admission, Therapeutic Intervention Scoring System (TISS) [6] and Simplified Acute Physiology Score (SAPS) [7] results upon admission, origin and duration of the infectious process (if the patient had one), the day when polyneuropathy developed after admission to the ICU, a complete neurological examination performed initially and during the patient's stay in the ICU, the length of stay in the ICU, and the development of diverse organ failure. The following modified criteria were used $[8,9]$. Respiratory failure: arterial oxygen tension $\left(\mathrm{PaO}_{2}\right)$ less than $60 \mathrm{mmHg}$ and inspired oxygen concentration $\left(\mathrm{FiO}_{2}\right)$ higher than 0.4 or the need for mechanical ventilation for more than $48 \mathrm{~h}$. Circulatory failure: heart failure, shock or the need for vasoactive drugs for more than $24 \mathrm{~h}$. Renal failure: plasma creatinine higher than $2 \mathrm{mg} / \mathrm{dL}$ in the absence of a previous renal disease. Hepatic failure: serum bilirubin level increased by $3 \mathrm{mg} / \mathrm{dL}$ over baseline or serum transaminases levels greater than twice normal. Hematological failure: thrombocytopenia with a platelet count of less than 100000 per $\mathrm{mm}^{3}$ or prothrombin time or partial thromboplastin time 1.5 times the normal control value. Neurological failure: coma without a previous neurological injury and in absence of sedative drugs. Metabolic failure: hypoproteinemia (serum total proteins less than $5.5 \mathrm{~g} / \mathrm{dL}$ ) or hyperglycemia (plasma glucose over $200 \mathrm{mg} / \mathrm{dL}$ ) or metabolic acidosis. We performed the following microbiological studies: blood cultures, bronchial secretion and exudate cultures, serum antibodies against Legionella, Epstein Barr virus, Herpes zoster, Cytomegalovirus, and hepatitis B were measured.

When a clinical diagnosis of polyneuropathy was made, plasma samples were taken for analysis of urea, glucose, creatinine, sodium, potassium, calcium, phosphorus, magnesium, zinc, copper, manganese, chromium, vitamins $B_{12}, E$, and $C$, total proteins, albumin, transferrin, rheumatoid factor, LE cell test, and thyroid function tests (Free T 4 Index and T 3 Resin Uptake). Levels of total porphyrins were determined from urine samples. A lumbar puncture with cerebrospinal fluid analysis of proteins, glucose, cells, and culture was performed.

All patients underwent an electrophysiological study consisting of an electromyographic assessment of muscular activity at rest and during contraction in the muscles of upper and lower limbs using concentric needle electrodes.

In addition, motor and sensory nerve conduction velocities, $F$ waves, distal motor latencies and distal sensory action potentials of peripheral nerve were obtained using needle electrodes near nerve tissue and electronic averaging systems [10]. Muscle biopsies were performed on two patients and a sural nerve biopsy was done on a third patient. 
All patients required mechanical ventilation and Positive End-Expiratory Pressure (PEEP) for ARF and had pulmonary artery catheterization using a Swan-Ganz catheter. Nutrition was given parenterally in four cases, and enterally in one, by way of a nasogastric tube. Vitamin supplements, electrolytes and trace elements were given. Nitrogen balance was maintained throughout the treatment period.

Due to the reduced size of the patients group and the absence of a control group, a descriptive statistical analysis was performed using average values and standard deviation of the parameters.

\section{Results}

Of a total of 330 patients admitted to our ICU over an eleven month period (June 1987-April 1988) five patients ( 4 males and 1 female) with acute polyneuropathic symptoms were studied. The study excludes a patient who presented with a clinical and electromyographic pattern typical of Guillain-Barré syndrome before admission to ICU.

Average age of the patients was $65.0 \pm 5.6$ years. The cause of admission was ARF in three cases ( 2 for pneumonia and 1 for thoracic trauma) and purulent postoperative peritonitis in two cases. The patient with the thoracic trauma developed severe respiratory infection a few days after admission (Table 1). The mean value of TISS and SAPS results on admission were $51.0 \pm 15.2$ and $14.6 \pm 2.3$ respectively. The length of the infectious symptoms, as characterized by leucocytosis and persistent fever above $38^{\circ} \mathrm{C}$, was $16.0 \pm 4.3$ days.

The results of the neurological examination performed on all the patients upon admission were normal. The clinical diagnosis of polyneuropathy was made an average of $16.4 \pm 4.7$ days after hospitalization. All patients presented with a symmetrical paresis with hypotonia, hyporeflexia and conserved tactile sensitivity in the upper and lower limbs with a predominantly distal distribution, without disturbance of the cranial nerves. The average stay in the ICU was $37.8 \pm 6.8$ days. Two patients died as a consequence of their infectious process, while the three survivors showed evidence of severe motor impairment due to polyneuropathy.

The appearance of organ failure is shown in Table 2. Four patients developed multiorgan failure (defined as the presence of organ failure in 3 or more organs).

In reference to the ARF suffered by the 5 patients, catheterization of the pulmonary artery with Swan-Ganz catheters showed the following values (mean \pm s.d.): mean pulmonary artery pressure $25.1 \pm 2.3 \mathrm{mmHg}$, mean pulmonary capillary wedge pressure $10.6 \pm 2.3 \mathrm{mmHg}$, pul-

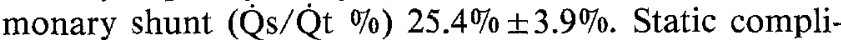
ance values (mean \pm s.d.) were $31.6 \pm 3.0 \mathrm{ml} / \mathrm{cmH}_{2} \mathrm{O}$.

The $\mathrm{FiO}_{2}$ and PEEP levels necessary to achieve an adequate $\mathrm{PaO}_{2}$ were $0.6 \pm 0.1$ and $10.4 \pm 0.9 \mathrm{cmH}_{2} \mathrm{O}$ respectively. All patients showed diffuse bilateral alveolar infiltrates on the chest X-ray. These hemodynamic, gas exchange, mechanical respiratory, and radiographic values are considered diagnostic of Adult Respiratory Distress Syndrome (ARDS) [11]. All patients required prolonged mechanical ventilation, for an average of $26.6 \pm 3.3$ days. In the 4 patients in whom weaning was achieved, the procedure was difficult and prolonged, taking $7.0 \pm 0.8$ days.
Table 1. Clinical features

\begin{tabular}{|c|c|c|c|}
\hline Patient & $\begin{array}{l}\text { Reason for } \\
\text { admission }\end{array}$ & Principal disorder & Course \\
\hline 1 & $\mathrm{ARF}$ & $\begin{array}{l}\text { Community acquired } \\
\text { pneumonia group B- } \\
\text { Streptococcus }\end{array}$ & Died \\
\hline 2 & $\mathrm{ARF}$ & $\begin{array}{l}\text { Community acquired } \\
\text { pneumonia undetermined } \\
\text { bacteria }\end{array}$ & Died \\
\hline 3 & $\mathrm{ARF}$ & $\begin{array}{l}\text { Thoracic trauma, hospi- } \\
\text { tal acquired pneumonia- } \\
\text { E. coli }\end{array}$ & $\begin{array}{l}\text { Survived } \\
\text { moderate motor } \\
\text { deficiency }\end{array}$ \\
\hline 4 & $\begin{array}{l}\text { Postoperative } \\
\text { peritonitis }\end{array}$ & IAI & $\begin{array}{l}\text { Survived } \\
\text { severe motor } \\
\text { deficiency }\end{array}$ \\
\hline 5 & $\begin{array}{l}\text { Postoperative } \\
\text { peritonitis }\end{array}$ & IAI & $\begin{array}{l}\text { Survived } \\
\text { moderate motor } \\
\text { deficiency }\end{array}$ \\
\hline
\end{tabular}

Key: $\mathrm{ARF}=$ Acute respiratory failure; $\mathrm{IAI}=$ Intra-abdominal infection

All of the blood cultures and serum antibody studies were negative. A pleural fluid culture showed growth of a beta-hemolytic Streptococcus in one of the patients with community acquired pulmonary infection, while microbiological studies on the other patient with the same type of infection were negative. In the patient with hospital acquired pulmonary infection following thoracic trauma, Escherichia coli were cultured from bronchial secretions. Cultures of the peritoneal exudates showed growths of Escherichia coli in both patients with purulent peritonitis. The results of the plasma and urine determinations performed are shown in Table 3 . The rheumatoid factor and LE cell tests were negative in all the patients.

The CSF studies showed protein and glucose values to be normal in the five patients. The cell counts were less than 5 cells $/ \mathrm{m}^{3}$ in four patients, and 20 cells $/ \mathrm{m}^{3}$ (all lymphocytes) in the remaining case.

In the electromyographic examination performed on each patient, we observed a severe loss of motor units with signs of active denervation as shown by the presence of fibrillation potentials and positive waves in the mus. cles which were tested. In the nerve conduction velocity studies, normal distal motor latencies were observed in al patients except one. Motor and sensory conduction veloc. ities were for the most part normal or slightly slowed. The

Table 2. Organ failure in patients with polyneuropathy

\begin{tabular}{ll}
\hline Organ failure & Patient \\
\hline Respiratory & 5 \\
Circulatory & 2 \\
Renal & 2 \\
Hepatic & 2 \\
Hematological & 2 \\
Neurological & 4 \\
Metabolic & 4 \\
Multiorgan failure $^{a}$ & 4 \\
\hline
\end{tabular}

${ }^{\text {a }}$ Multiorgan failure $=$ organ failure in 3 or more organs 
Table 3. Laboratory findings in the patients with polyneuropathy

\begin{tabular}{lcl}
\hline & Values obtained $^{\mathrm{a}}$ & Normal values \\
\hline Urinary porphyrins & $104.0 \pm 10.0$ & $<200 \mathrm{mcg} / 24 \mathrm{~h}$ \\
Phosphorus & $3.4 \pm 1.2$ & $2.5-4.5 \mathrm{mg} / \mathrm{dL}$ \\
Magnesium & $0.84 \pm 0.26$ & $0.6-1.3 \mathrm{mmol} / \mathrm{L}$ \\
Zinc & $72.7 \pm 20.7$ & $60-150 \mathrm{mcg} / \mathrm{dL}$ \\
Copper & $130.2 \pm 37.0$ & $70-140 \mathrm{mcg} / \mathrm{dL}$ \\
Manganese & $3.2 \pm 1.2$ & $<5 \mathrm{mcg} / \mathrm{dL}$ \\
Chromium & $1.0 \pm 0.1$ & $<1 \mathrm{mcg} / \mathrm{dL}$ \\
Vitamin $B_{12}$ & $9751.7 \pm 78316.1$ & $210-920 \mathrm{pg} / \mathrm{mL}$ \\
Vitamin E & $5.9 \pm 0.2$ & $5-20 \mathrm{mcg} / \mathrm{dL}$ \\
Vitamin C & $2.0 \pm 0.7$ & $0.4-2 \mathrm{mg} / \mathrm{dL}$ \\
Free T4 Index & $9.3 \pm 2.5$ & $4.8-11.9 \mathrm{mcg} / \mathrm{dL}$ \\
T3 Resin uptake & $0.79 \pm 0.1$ & $0.72-1.24 \mathrm{units}$ \\
\hline
\end{tabular}

${ }^{a}$ Values displayed are mean $\pm \mathrm{SD}$

absence of $F$ waves, diminished amplitude of compound muscle action potential, especially in the legs and slight anomalies in the distal sensory action potential, all suggested a process with a predomination of axonal degeneration of the peripheral nerves, most affecting the motor component [12].

The nerve biopsy showed a reduction of myelinated thick fibers with no inflammatory infiltrates, myelin ovoids, and areas of segmentary demyelination and remyelination. Both muscle biopsies revealed the absence of inflammation and signs of muscular atrophy.

Prior to the diagnosis of polyneuropathy and in spite of nutritional support, the patients showed a tendency to have a negative nitrogen balance accompanied by deterioration in the studied nutritional parameters (Table 4).

\section{Discussion}

The appearance of cases of acute polyneuropathy (with predominantly axonal involvement) in ICU patients with other infectious processes and ARF has previously been described $[1,2-4,13,14]$. There is no profound understanding of the process which can occur in up to $50 \%$ of patients with severe infectious processes lasting more than 2 weeks [15]. During our study patients with polyneuropathy constituted $17.2 \%$ of all patients admitted to the ICU with severe infectious processes, and $38.4 \%$ of those patients whose stay was over 20 days.

It can be difficult to make a diagnosis when dealing with critically ill patients who have an active infectious process and are undergoing mechanical ventilation. The clinical characteristics of polyneuropathy are loss of strength and hyporeflexia of the limbs and in particular, difficulty in weaning $[1,15,16]$.

Sensory involvement is variable, patients do not usually exhibit evidence of autonomic dysfunction and approximately $20 \%$ of cases have facial muscle impairment [13].

The cerebrospinal fluid glucose, protein and cell counts were generally normal, although there was a slight elevation in the protein value in some cases $[1,3]$. One of our patients showed a slight rise in predominately lymphocytic cells, as has been described in other cases of polyneuropathy [1].
Four of our patients, as previously reported $[1,3-5$, 13], developed an encephalopathy, seen as coma, sometimes accompanied by convulsions, before the development of the polyneuropathy. These features were reversible and may directly be related to the same central or peripheral neurological damage or be due to so-called septic encephalopathy [17], a functional disturbance produced by toxic and metabolic disorders without a characteristic organic lesion. Although in other structural studies [14] no lesions were present in several of the cases of encephalopathy, diffuse micro-abscesses, central pontine myelinolysis, diffuse micro-hemorrhages, and multiple cerebral infarctions were encountered in others [18].

The electromyographic tests showed clear signs of axonal degeneration [1, 13]. Histological studies revealed axonal degeneration without inflammatory changes near the nerve and signs of muscular atrophy, because of denervation, as well as primary muscular changes independent of the nervous system $[1,13,14]$ probably related to the septic process $[14,19]$. Patients may completely recover if the primary infectious process is overcome, even though clinical and electrophysiological abnormalities continue to be present for a considerable period following the acute phase $[2,13,14]$.

All the patients studied had clinical, analytic, and electromyographic data similar to cases previously described by other authors, and their nutritional abnormalities and substantial catabolic increase must be pointed out. The histological finding of reduction of myelinated thick fibers with no inflammatory infiltrates, areas of demyelination and remyelination, and myelin ovoids are typical of axonal damage.

The polyneuropathy shows several similarities to the Guillain-Barré syndrome, although differences have been established [13] based fundamentally on electromyographic data, in which a clear pattern of axonal deterioration contrasts with the demyelinating pattern of the Guillain-Barré syndrome. Further differences are based on cerebrospinal fluid analysis, which shows protein elevation with albumin-cytological dissociation, while in the polyneuropathy of critically ill patients, the cerebrospinal fluid is usually normal, except for slight protein elevation occasionally. Finally, histological findings which show areas of axonal degeneration without inflammatory changes establish additional differences with the Guillain-Barré syndrome. In spite of these differences and because some cases of Guillain-Barré syndrome with an axonal pattern have been described [20], polyneuropathy in critically ill patients could be regarded as a variant of this syndrome [21].

Table 4. Nutritional parameters

\begin{tabular}{lcc}
\hline Parameter & Values obtained $^{\mathrm{a}}$ & Normal values \\
\hline Total proteins & $5.4 \pm 0.7$ & $5.5-8 \mathrm{~g} / \mathrm{dL}$ \\
Albumin & $2.1 \pm 0.3$ & $3.5-5.5 \mathrm{~g} / \mathrm{dL}$ \\
Transferrin & $0.95 \pm 0.35$ & $1.5-3 \mathrm{~g} / \mathrm{L}$ \\
Lymphocytes & $890 \pm 384$ & $1500-4000 / \mathrm{mm}^{3}$ \\
\hline
\end{tabular}

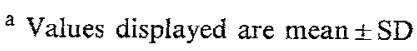


Many factors have been implicated in the aetiology of polyneuropathy. Toxic and common infectious factors which are responsible for acute impairment of peripheral nerves [1] have been dismissed. Nutritional and metabolic factors may relate to the true cause of polyneuropathy. Some cases have demonstrated marked improvement of neurological symptoms related to the introduction of an adequate diet [1]. No concrete evidence of any particular nutritional deficit has been demonstrated [1].

The appearance of a series of phenomena which affect various organs which has been termed multiorganic failure has been referred to when dealing with severe infectious processes [8]. The cause of this syndrome seems to be a disorder of the oxidative metabolism at the cellular level produced by hypoxia secondary to hypoperfusion. This produces an alteration of the basic source of energy for cellular metabolism, namely ATP. An increase in the use of ATP takes place, which causes ADP and AMP to accumulate; they are then catabolized into degraded products of purine, and, because of the hypoxia, can cross cell membranes and may directly produce cellular damage [22].

This mechanism of tissue damage to various organs in patients with severe infections could be the same occurring at the peripheral nerve level. This cellular disorder has already been demonstrated, supported by an important reduction of high energy phosphorylated components in skeletal muscle [15]. The nerve cell body is the production site for nutrients destined for the peripheral nerve axon. The axon is involved in bidirectional exchanges of nutrients between the neuronal body and distal arborescences. This cellular energy metabolism and the integrity of this flow are essential to maintain the integrity of the nerve fiber [23].

On the other hand, the fact that ARDS appears in all our cases suggests a mechanism for polyneuropathy similar to that implicated in the development of this syndrome [24].

In conclusion, cases of predominately axonal peripheral polyneuropathy in patients with prolonged infection and ARF are a relatively frequent occurrence and the cause has not been determined, although it appears to be related to one of the metabolic disorders induced by the infection. Our data in this study is consistent with other reports in associating an important nutritional disorder with these patients. In patients with severe infection accompanied by organ dysfunction, in particular ARDS, careful attention must be paid to adequate nutritional support and to controlling the catabolic state accompanying these situations.

\section{References}

1. Bolton CF, Gilbert JJ, Hahn AF, Sibbald WJ (1984) Polyneuropathy in critically ill patients. J Neurol Neurosurg Psychiatry 47:1223-1231

2. Roelofs RI, Cerra F, Bielka N (1983) Prolonged respiratory insufficiency due to acute motor neuropathy: a new syndrome? Neurology 33 [Suppl 2]:240

3. Alonso P, Monasterio F, Lopez Messa JB, Sanchez García M, Montalvo M, Rojo $P$ (1986) Polineuropatía en pacientes sépticos. Medicina Intensiva [Supp] julio]:100-101
4. Williams AC, Sturman S, Kelsey S, Curran FT, Finnegan JA (1986) The neuropathy of the critically ill. Br Med J 293:790-791

5. Alonso, Alonso P, Monasterio Chicharro F, Lopez-Messa JB, Sanchez Garcia M, Montalvo Burbano M, Rojo Alaminos P (1987) Critically ill polyneuropathy. Crit Care Med 15:1162

6. Roberta Kenn A, Cullen DJ (1983) Therapeutic intervention scoring system: update 1983. Crit Care Med 11:1-3

7. Le Gall JR, Loirat P, Alperovitch A (1983) Simplified acute physiology score (letter). Lancet II:741

8. Pine RW, Wertz MJ, Lennard S, Dellinger EP, Carrico J, Minsheq BH (1983) Determinants of organ malfunction of death in patients with intra-abdominal sepsis. A discriminant analysis. Arch Surg 118:242-249

9. Abizanda R, Jorda R, Verduras MA, Abadal JM, Revuelta P, Chama A (1985) Fracaso Multiorgánico (FMO). Qué? Cuándo? Por qué? Medicina Intensiva 9:213-219

10. Trojaborg W (1964) Motor nerve conduction velocities in norma] subjects with particular reference to the conduction in proximal and distal segments of median and ulnar nerve. Electroenceph Clin Neurophysiol 17:314-321

11. Carlet J (1985) Criterios diagnosticos y etiológicos del síndrome de distrés respiratorio agudo del adulto. In: Lemaire F, Artigas A (eds) El síndrome de distrés respiratorio agudo del adulto. Masson, Barcelona Paris, pp $1-10$

12. McLeod JG, Prineas JW, Walsh JC (1973) The relationship of conduction velocity to pathology in peripheral nerves. In: Desmedt JE (ed) New developments in electromyography and clinical neurophysiology, vol 2. Karger, Basel, pp 249-258

13. Bolton CF, Laverty DA, Brown JD, Witt NJ, Hahn AF, Sibbald WJ (1986) Critically ill polyneuropathy: electrophysiological studies and differentiation from Guillain-Barré syndrome. J Neurol Neurosurg Psychiatry 49:563-573

14. Zochodne DW, Bolton CF, Wells GA, Gilbert JJ, Hahn AF, Brown JD, Sibbald WA (1987) Critical illness polyneuropathy. A complication of sepsis and multiple organ failure. Brain 110:819-842

15. Bolton CF, Zochodne DW, Witt NJ (1987) The peripheral nervous system in sepsis and multiple organ failure. Crit Care Med 15 [Suppl]:447

16. Covert CR, Brodie SB, Zimmerman JE (1986) Weaning failure due to acute neuromuscular disease. Crit Care Med 14:307-308

17. Hasselgren PO, Fischer JE (1986) Septic encephalopathy. Etiology and management. Intensive Care Med 12:13-16

18. Graham DI, Behan PO, More AR (1979) Brain damage complicating septic shock. Acute haemorrhagic leucoencephalitis as a complication of the generalised Shwartzman reaction. J Neuro] Neurosurg Psychiatry 42:19-28

19. Clowes Jr GHA, George BC, Villee Jr CA, Saravis CA (1983) Muscle proteolysis induced by a circulating peptide in patients with sepsis or trauma. N Engl J Med 308:545-552

20. Feasby TE, Gilbert JJ, Brown WF, Bolton CF, Hahn AF, Koopman WF, Zochodne DW (1986) An acute axonal form of Guillain-Barré polyneuropathy. Brain 109:1115-1126

21. Asbury AK (1981) Diagnostic considerations in Guillain-Barré syndrome. Ann Neurol 9 [Suppl]:1-5

22. Grum CM, Simon RH, Dantzker DR, Fox IH (1985) Evidence for adenosine triphosphate degradation in critically-ill patients. Chesi $88: 763-767$

23. Spencer PS, Sabri MI, Schaumburg HH, Moore CL (1979) Does a defect of energy metabolism in the nerve fibre underlie axonal degeneration in polyneuropathies? Ann Neurol 5:501-507

24. Tenaillon A, Salmona JP, Burdin M, Poirier A (1985) Patogenia de] sindrome de distrés respiratorio agudo del adulto. In: Lemaire $F$, Artigas A (eds) El sindrome de distrés respiratorio agudo del adulto. Masson, Barcelona Paris, pp 1-27

Dr. J. B. Lopez Messa

Intensive Care Unit

Hospital General "Río Carrión"

Ave. Ponce de León $s / n$

E-34005 Palencia

Spain 